\title{
Biological and clinical characteristics of patients with chronic lymphocytic leukemia with the IGHV3-21 and IGHV1-69: analysis of data from a single center
}

\author{
R. URBANOVA ${ }^{1, \star}$, L. HUMPLIKOVA ${ }^{2}$, H. DRIMALOVA ${ }^{1}$, V. PROCHAZKA ${ }^{1}$, P. TURCSANYI ${ }^{2}$, Z. PIKALOVA ${ }^{1}$, M. HOLZEROVA ${ }^{1}$, L. KRUZOVA ${ }^{1}$, \\ M. JAROSOVA ${ }^{1}$, J. URBAN ${ }^{3}$, J. VRBKOVA ${ }^{4}$, K. INDRAK ${ }^{1}$, T. PAPAJIK ${ }^{1}$
}

${ }^{1}$ Department of Hemato-Oncology, Faculty of Medicine and Dentistry, Palacky University Olomouc; ${ }^{2}$ Department of Hemato-Oncology, University Hospital Olomouc; ${ }^{3}$ Department of Physiotherapy, Faculty of Physical Culture, Palacky University Olomouc; ${ }^{4}$ Institute of Molecular and Translational Medicine, Faculty of Medicine and Dentistry, Palacky University Olomouc

*Correspondence: urbano@fnol.cz

Received August 27, 2014 / Accepted January 12, 2015

\begin{abstract}
This study aimed at mapping the frequency of IGHV3-21 and IGHV1-69 in a group of 417 patients newly diagnosed with chronic lymphocytic leukemia (CLL) and described basic characteristics, cytogenetic abnormalities and prognosis of these patient subgroups. IGHV3-21 was found in 29 patients (7\%) and IGHV1-69 in 51 patients (12.4\%). The median overall survival (OS) rates were 97 months and 85 months in the IGHV3-21 and IGHV1-69 groups, respectively. In this small group of patients, the study failed to show a difference in OS of IGHV3-21 patients with mutated and unmutated IGHV status ( $\mathrm{p}<0.597)$. There was also no difference in OS between IGHV3-21 patients with mutated IGHV status and all patients in the group having unmutated IGHV status $(\mathrm{p}<0.245)$. On the other hand, patients with IGHV3-21 and the presence of some other adverse prognostic factors (age $\geq 65$ years, lymphocyte count $\geq 50 \times 109 / \mathrm{L}$, serum thymidine kinase $\geq 9 \mathrm{U} / \mathrm{L}$, deletion of $17 \mathrm{p}$ ) had statistically significantly worse OS than IGHV3-21 patients without the presence of these prognostic factors. The multivariate analysis of an entire group of Binet clinical stage A patients proved that the presence of IGHV3-21 is as an independent adverse prognostic factor even though there was no statistical difference in OS between patients with IGHV3-21 and those without IGHV3-21 in the entire group $(\mathrm{p}<0.769)$. Patients with IGHV1-69 had the same probablility of OS irrespective of the presence of other adverse prognostic factors; their OS was significantly shorter as compared with the other patients from the entire group $(\mathrm{p}<0.03)$.

The study mapped the occurrence of recurrent cytogenetic changes detected by FISH in IGHV3-21 (subset \#2 and non-subset \#2) and IGHV1-69 and compared it with the occurrence of recurrent changes in the entire group of patients. In IGHV1-69 and in subset \#2 IGHV3-21, higher proportions of deletion of 11q were found (30\% and 31\%, respectively), with the deletion being present in $19.2 \%$ of the entire group of patients. None of the 3 patients with IGHV3-21 and deletion of 17p had subset \#2. Patients with subset \#2 IGHV3-21 had higher proportions of deletion of 13 (69\%) as compared with non-subset \#2 IGHV3-21 patients (27\%).
\end{abstract}

Key words: chronic lymphocytic leukemia, IGHV mutation status, IGHV3-21, IGHV1-69, stereotyped B-cell receptor, subset \#2

Chronic lymphocytic leukemia (CLL) is a biologically heterogeneous disease with variable clinical course. It is indolent in some patients but aggressive in others. The likely course and clinical activity of the disease and probability of survival in a particular patient may be predicted using numerous prognostic factors.

Two biologically and prognostically different CLL subgroups are defined by the presence or absence of somatic hypermutations (SHMs) in the immunoglobulin heavy chain variable region $(I G H V)$. The first subtype includes diseases with mutated (M) IGHV status (originating from post-germinal B-cells) and the other subtype is represented by diseases with unmutated (UM) IGHV status (originating from pregerminal B-cells). SHMs in IGHV genes are detected in as many as $50 \%$ to $70 \%$ of patients diagnosed with CLL [1]. UM IGHV status is characterized by at least $98 \%$ sequence 
homology to the corresponding germline gene. It is associated with the patients' unfavorable prognosis and shorter overall survival (OS) when compared with individuals having SHMs of the gene $[2,3]$.

The extent of IGHV rearrangements is limited in CLL tumor cells as compared with normal B-cells. Numerous studies reported preferential presence of certain variable region $(\mathrm{VH})$ gene segments in patients with this disease. This may support the theory of the role of specific antigen stimulation which may lead to a leukemogenesis $[4,5]$. In this respect, some studies do not rule out the role of autoantigens in the pathogenesis of CLL [6]. The most common VH genes present in CLL patients are members of the VH3, VH4 and VH1 families $[7,8]$. Somatic mutations are not uniform within various $\mathrm{VH}$ families. More mutations have been observed in VH3 family V subgenes as compared with V subgenes from the VH1 family. VH1 family subgenes tend to be mostly unmutated [9]. Selected V gene segments have prognostic value in CLL. These include IGHV3-21 and IGHV1-69 [5, $10,11]$. The presence of IGHV3-21 in CLL is associated with poor prognosis regardless of its mutation status. Patients with this subgene tend to have shorter OS (as do patients with UM $I G H V$ genes) despite the fact that two thirds of patients from this group have M IGHV $[5,10]$. Approximately one-half of IGHV3-21 patients have stereotyped B-cell receptor (BCR), known as subset \#2, with a short and highly similar CDR3 (9 amino acids long) and usage of one particular IG lambda gene, IGLV3-21 [5]. Survival of patients (with both stereotyped and non-stereotyped receptors) is short regardless of IGHV mutation status $[5,12,13]$. Patients with stereotyped BCR have a shorter progression-free survival $[14,15]$. Another study compared the occurence of recurrent aberrations detected by fluorescence in situ hybridization (FISH). In patients with subset \#2, deletions of 13q (13q-) were frequently detected (79\%), as compared with non-subset \#2 patients (31\%). Additionally, deletion of $11 \mathrm{q}(11 \mathrm{q}-)$ was also more frequently (31\%) detected in patients with subset \#2. According to the study, deletion of $17 \mathrm{p}(17 \mathrm{p}-)$ was only detected in a single non-subset \#2 patient $[16,17]$.

In the vast majority of CLL patients, presence of the IGHV169 is associated with UM IGHV status. Due to that fact, the presence of IGHV1-69 is related to unfavorable prognosis. Patients with this subgene appear to be a homogeneous group, with more frequent advanced clinical stage of the disease requiring early therapeutic intervention. However, their survival is not worse than that of other patients with UM IGHV [11]. It was found that IGHV1-69 is expressed by $30 \%$ of unmutated CLL and rearranges to a restricted number of IGHD and IGHJ genes, often generating long and rather similar HCDR3 regions [18]. This suggests that environmental antigens play a role in the development and/or progression of CLL [19].

This retrospective study aimed at describing the basic biological and clinical characteristics, prognosis and response to treatment in a group of patients with newly diagnosed CLL and IGHV3-21 and IGHV1-69. The goals were to (1) describe the proportion of $\mathrm{VH}$ families in the entire group of 417 patients, and map the presence of IGHV3-21 and IGHV169; (2) characterize groups of patients with IGHV3-21 and IGHV1-69 with respect to IGHV mutation status, describe the proportion of cytogenetic changes - 11q- and $17 \mathrm{p}-$, and describe the clinical picture and course of the disease - i.e. the clinical stage, clinical activity, potential need to initiate therapy and treatment response achieved; (3) compare the OS of patients with and without the presence of IGHV3-21 as well as those with and without the presence of IGHV1-69 and to compare the OS of IGHV3-21 and IGHV1-69 patients; and (4) determine the OS in IGHV3-21 and IGHV1-69 depending on the presence of the other predictive factors (age, gender, lymphocyte count, hemoglobin level, disease stage, beta-2-microglobulin [B2M], serum thymidine kinase [sTK], $I G H V$ mutation status, presence of $11 \mathrm{q}-$ and $17 \mathrm{p}-$ ) and, in IGHV3-21 individuals, also depending on the presence of stereotyped BCR.

\section{Materials and methods}

The study group comprised 417 patients (270 males and 147 females) with newly diagnosed CLL in accordance with the National Cancer Institute (NCI) criteria who were followed or treated in our center in 2000-2011 and in whom IGHV mutation status was determined. The median age of the group was 61 years (range, 27-87 years).

Genetic analysis. The material for cytogenetic and molecular cytogenetic tests was peripheral blood cells. In all patients, classical cytogenetic analysis was carried out. Chromosomal aberrations 11q-, 17p-, 13q-and trisomy 12 were detected by FISH using gene and centromeric probes. To verify and precisely characterize chromosomal changes in the karyotype, whole chromosome probes were used. The comparative genomic hybridization (CGH) method was performed in selected patients with complex karyotypes or in those with unbalanced chromosomal changes that could not be detected by classical cytogenetic methods and FISH. Complex karyotypes were defined as findings of three and more clonal aberrations in a karyotype. CGH was carried out according to the manufacturer's instructions as described earlier [20].

Immunoglobulin gene rearrangement analysis. Sequence analysis of the $I G H V$ genes was performed as described previously [21, 22]. IGHV sequences were aligned to ImMunoGeneTics directory and considered mutated if their identity to corresponding germline genes was $98 \%$. Further details are reported in supplemental Methods.

Serum markers. The normal range of B2M was $0.8-2.34 \mathrm{mg} / \mathrm{L}$ and the normal range of sTk was 0-9U/L.

Statistical analysis. The primary end points were OS. OS was estimated using Kaplan-Meier plots and compared between groups by log-rank test. Univariate and multivariate Cox models were used to verify independent prognostic power of each parameter. 
The study was performed in accordance with the 2008 revision of the Declaration of Helsinki. All patients gave informed consent to the examination and anonymous processing of data on their disease.

\section{Results}

Of the 417 patients, the largest proportions were in the VH3 (49.6\%) and VH1 (25.9\%) gene subfamilies (Table 1). The IGHV3-21 subgene was present in 29 patients, that is,

Table 1. VH gene family usage in all chronic lymphocytic leukemia patients $(\mathrm{N}=417)$

\begin{tabular}{ccc}
\hline VH gene family & Patients (N) & Patients (\%) \\
\hline VH1 & 108 & 25.9 \\
VH2 & 12 & 2.8 \\
VH3 & 207 & 49.6 \\
VH4 & 71 & 17 \\
VH5 & 15 & 3.6 \\
VH6 & 1 & 0.2 \\
\hline
\end{tabular}

$7 \%$ of the entire group. The IGHV1-69 subgene was present in 51 patients, i.e. $12.2 \%$ of the entire group. The median age of patients with the IGHV3-21 subgene was 62.8 years (range, 35.6-78.7 years); the subgroup comprised 16 males (55\%) and 13 females (45\%). Binet A stage was diagnosed in 7 patients (27\%), Binet B in 10 patients (38\%) and Binet $\mathrm{C}$ in 9 patients (35\%). The median lymphocyte count was $35.8 \times 10^{9} / \mathrm{L}$ (range, $5.2-346.0 \times 10^{9} / \mathrm{L}$ ). In this group, $45 \%$ of patients had an UM IGHV sequence and 55\% had a M IGHV sequence. A total of 13 patients had stereotyped IGHV3-21 (subset \#2), of whom 8 (62\%) had M IGHV status. The mean number of $I G H V$ mutations in patients with $\mathrm{M} I G H V$ status was $3.58 \%$. The median B2M level was $3.61 \mathrm{mg} / \mathrm{L}$ (range, $1.77-9.29 \mathrm{mg} / \mathrm{L})$. Six patients were found to have a deletion of $11 \mathrm{q}(21.4 \%$ of the examined patients) and 3 patients were detected with a deletion of $17 \mathrm{p}$ (10.7\% of the examined patients). The median follow-up of the group was 58 months (range, 10-136 months).

For active disease as defined by 1996 NCI recommendations, therapy was initiated in 26 of patients (90\%) [23]. By the date of analysis, 14 patients (48\%) with IGHV3-21 had died. The median time of treatment initiation in the IGHV321 group was 8.9 months (range, 4.1-63.0 months) and the

Table 2. Characteristics of patients with the IGHV3-21 and IGHV1-69 subgenes

\begin{tabular}{|c|c|c|c|c|c|c|c|c|}
\hline \multirow[b]{2}{*}{ Characteristic } & \multicolumn{4}{|c|}{ IGHV3-21 $(\mathrm{N}=29)$} & \multicolumn{4}{|c|}{$I G H V 1-69(\mathrm{~N}=51)$} \\
\hline & $\mathrm{Me}$ & No & Range & $\%$ & $\mathrm{Me}$ & No & range & $\%$ \\
\hline Age & 62.8 & & $35.6-78.7$ & & 59.5 & & $36.1-83.0$ & \\
\hline males/females & & $16 / 13$ & & $57 / 43$ & & $39 / 12$ & & $77 / 23$ \\
\hline lymphocytes $\left(10^{9} / \mathrm{L}\right)$ & 35.8 & & $5.2-346.0$ & & 35.5 & & $6.4-1115.0$ & \\
\hline Binet $\mathrm{A} / \mathrm{B} / \mathrm{C}$ stage & & $7 / 10 / 9$ & & $27 / 38 / 35$ & & $15 / 22 / 9$ & & $33 / 48 / 19$ \\
\hline$I G H V \mathrm{UM} / \mathrm{M}$ & & $13 / 16$ & & $45 / 55$ & & $50 / 1$ & & $98 / 2$ \\
\hline $\mathrm{B} 2 \mathrm{M}(\mathrm{mg} / \mathrm{L})$ & 3.61 & & $1.77-9.29$ & & 3.19 & & $1.31-7.97$ & \\
\hline$<2.34$ & & 5 & & 22 & & 8 & & 19 \\
\hline$\geq 2.34$ & & 18 & & 78 & & 34 & & 81 \\
\hline sTk (U/L) & 18.7 & & $5.2-101.0$ & & 18.4 & & $3.4-101.0$ & \\
\hline$<9$ & & 5 & & 23 & & 11 & & 26 \\
\hline$\geq 9$ & & 17 & & 77 & & 31 & & 74 \\
\hline $11 q-$ & & 6 & & 21.4 & & 12 & & 30 \\
\hline $17 \mathrm{p}-$ & & 3 & & 10.7 & & 3 & & 7.1 \\
\hline Stereotyped BCR subset \#2 & & 13 & & 14.2 & & & & \\
\hline Treated & & 26 & & 90 & & 42 & & 82 \\
\hline TFS (months) & 8.9 & & $4.1-63.0$ & & 9.0 & & $2.2-29.8$ & \\
\hline \multicolumn{9}{|l|}{ primary therapy } \\
\hline $\mathrm{CLB} /(\mathrm{R}) \mathrm{FC} /(\mathrm{R}) \mathrm{C}(\mathrm{H}) \mathrm{OP}$ & & $8 / 11 / 7$ & & $31 / 42 / 27$ & & $4 / 32 / 6$ & & $10 / 76 / 14$ \\
\hline $\mathrm{CR} / \mathrm{PR} / \mathrm{SD} / \mathrm{PD}$ & & $7 / 9 / 6 / 2$ & & $30 / 37 / 25 / 8$ & & $8 / 14 / 8 / 7$ & & $22 / 38 / 22 / 19$ \\
\hline OS (months) & 97 & & 55-not reached & & 85 & & $61-128$ & \\
\hline Died & & 14 & & 48 & & 28 & & 55 \\
\hline Follow-up (months) & 58 & & $10-136$ & & 50.5 & & $7-140$ & \\
\hline
\end{tabular}


median OS in this group reached 97 months (range, 55 months - not reached).

The median age of patients with the IGHV1-69 subgene was 59.5 years (range, $36.1-83.0$ years). In this subgroup, 50 cases $(98 \%)$ had UM IGHV status and only 1 patient (2\%) had M IGHV status. There were 39 males (77\%) and 12 females (23\%). Binet A stage was diagnosed in 15 patients (33\%), Binet B in 22 patients (48\%) and Binet C in 9 patients (19\%). The median lymphocyte count was $35.5 \times 10^{9} / \mathrm{L}$ (range, $\left.6.4-1115.0 \times 10^{9} / \mathrm{L}\right)$. The median B2M level was $3.19 \mathrm{mg} / \mathrm{L}$ (range, 1.31-7.97 mg/L). Twelve patients were found to have a deletion of $11 \mathrm{q}(30 \%$ of the examined patients) and 3 patients had a deletion of $17 \mathrm{p}$ ( $7.1 \%$ of the examined patients). The median follow-up of the group was 50.5 months (range, 7-140 months) For active disease therapy was initiated in 42 patients (82\%) By the date of analysis, 28 patients (55\%) with the IGHV1-69 subgene had died. The median time to treatment initiation in the IGHV1-69 group was 9.0 months (95\% CI, 2.2-29.8 months) and the median OS in this group reached 85 months (95\% CI, 61-128 months) (Table 2). Treatment outcomes with the overall response rate (ORR) to the administered chemotherapy in the primary therapy are shown in the Table (Table 2).

Univariate analysis (log-rank test) showed neither a difference in OS between IGHV3-21 patients and those without IGHV3-21 ( $\mathrm{p}<0.769)$ (Figure 1A) nor a difference in OS between patients with M IGHV and those with UM IGHV status $(\mathrm{p}<0.597)$ (Figure 1B). Moreover, there was no difference in OS between IGHV3-21 patients with M IGHV status and the entire group of patients with UM IGHV status $(\mathrm{p}<0.245)$ (Figure 1C). By contrast, IGHV1-69 patients had a shorter OS than those without IGHV1-69 ( $<<0.03$ ) (Figure 1D); however, no difference in OS was shown between IGHV3-21 patients and IGHV1-69 patients $(\mathrm{p}<0.302)$ (Figure 1E).
In patients with IGHV3-21, the log-rank test showed a shorter OS in case of the presence of another risk factor (age $\geq 65$ years, $\mathrm{p}<0.001$; lymphocyte count $\geq 50 \times 10^{9} / \mathrm{L}, \mathrm{p}<0.05$; presence of deletion of $17 \mathrm{p}, \mathrm{p}<0.05$ ) (Table 3 ). The prognostic value of $\mathrm{B} 2 \mathrm{M}$ could not be established due to a small number of observations. Patients with IGHV1-69 had the same probability of OS irrespective of the presence of other adverse prognostic factors (age $\geq 65$ years, $\mathrm{p}<0.850$; lymphocyte count $\geq 50 \times 10^{9} / \mathrm{L}, \mathrm{p}<0.119 ; \mathrm{B} 2 \mathrm{M} \geq 2.34 \mathrm{mg} / \mathrm{L}, \mathrm{p}<0.975 ; \mathrm{sTk} \geq 9 \mathrm{U} / \mathrm{L}$, $\mathrm{p}<0.963$ ) (Table 3).

The log-rank test showed a shorter survival of IGHV3-21 and IGHV1-69 patients with a deletion of $17 \mathrm{p}$ than those without the deletion $(\mathrm{p}<0.05$ and $\mathrm{p}<0.001$, respectively) but no difference in survival of patients in both subgroups with and without deletion of $11 \mathrm{q}(\mathrm{p}<0.986$ and $\mathrm{p}<0.917$, respectively) (Supplementary Figure S1 A,B,C,D).

Results of univariate analysis of selected prognostic factors in the entire group of 417 patients with respect to OS are summarized in the Table. A shorter OS was demonstrated in patients aged $\geq 65$ years, with Binet $\mathrm{B}$ or $\mathrm{C}$ stages, lymphocyte count $\geq 30 \times 10^{9} / \mathrm{L}, \mathrm{B} 2 \mathrm{M} \geq 2.34 \mathrm{mg} / \mathrm{L}, \mathrm{sTk} \geq 9 \mathrm{U} / \mathrm{L}$, unmutated IGHV status, deletion of $17 \mathrm{p}(\mathrm{p}<0.001)$, deleletion of $11 \mathrm{q}$ $(\mathrm{p}<0.05)$ and in patients with IGHV1-69 (Table 4).

Multivariate analysis of the entire group of patients revealed a shorter OS in patients aged $\geq 65$ years $(\mathrm{p}<0.001)$, with lymphocyte count $\geq 50 \times 10^{9} / \mathrm{L}(\mathrm{p}<0.05)$, UM IGHV status $(\mathrm{p}<0.05)$ and deletion of $17 \mathrm{p}(\mathrm{p}<0.05)$, concordance index 0.669 (Table 4). Multivariate analysis of the group of patients with Binet A stage showed a shorter OS in patients aged $\geq 65$ years $(\mathrm{p}<0.001)$, with UM IGHV status $(\mathrm{p}<0.04)$ and presence of the IGHV3-21 subgene ( $\mathrm{p}<0.019)$, concordance index 0.736 .

Additionally, the study mapped the occurrence of recurrent cytogenetic changes detected by FISH in IGHV3-21 (subset \#2 and non-subset \#2) and IGHV1-69 and compared it with the

Table 3. Univariate analysis of the other prognostic factors in relation to OS in patients with the IGHV3-21 and IGHV1-69 subgenes

\begin{tabular}{|c|c|c|c|c|c|c|}
\hline & \multicolumn{6}{|c|}{ Univariate analysis } \\
\hline & \multicolumn{3}{|c|}{ IGHV3-21 } & \multicolumn{3}{|c|}{ IGHV1-69 } \\
\hline & HR & $95 \% \mathrm{Cl}$ & $\mathrm{p}$ & HR & $95 \% \mathrm{Cl}$ & $\mathrm{p}$ \\
\hline age $\geq 65$ years & 9.36 & $2.0-43.8$ & $<0.001$ & 1.8 & $0.48-2.41$ & $<0.850$ \\
\hline lymphocytes $\geq 50 \times 10^{9} / \mathrm{L}$ & 4.6 & $0.96-17.24$ & $<0.05$ & 1.93 & $0.83-4.48$ & $<0.119$ \\
\hline Binet $B, C$ stage & 2.95 & $0.64-13.65$ & $<0.149$ & 1.27 & $0.52-3.14$ & $<0.600$ \\
\hline $\mathrm{B} 2 \mathrm{M} \geq 2.34(\mathrm{mg} / \mathrm{L})$ & & & & 0.98 & $0.33-2.93$ & $<0.975$ \\
\hline$s T k \geq 9(\mathrm{U} / \mathrm{L})$ & 5.74 & $0.74-44.6$ & $<0.06$ & 1.2 & $0.38-2.79$ & $<0.963$ \\
\hline$I G H V \mathrm{M}$ & 0.75 & $0.26-2.16$ & $<0.597$ & & & \\
\hline $17 \mathrm{p}-$ & 4.7 & $0.90-24.46$ & $<0.05$ & 8.7 & $2.61-29.00$ & $<0.001$ \\
\hline $11 \mathrm{q}^{-}$ & 1.1 & $0.21-4.79$ & $<0.986$ & 0.95 & $0.38-2.37$ & $<0.917$ \\
\hline Stereotyped BCR, subset \#2 & 1.57 & $0.48-5.15$ & $<0.456$ & & & \\
\hline
\end{tabular}

OS - overall survival, B2M - beta-2-microglobulin, sTk - serum thymidine kinase, IGHV M - immunoglobulin heavy chain variable region mutated $(<98 \%$ identity to germline), 11q- - 11q deletion, 17p- - 17p deletion, BCR - B-cell receptor, subset \#2 - classified according to defined criteria [5] HR - hazard ratio, $95 \% \mathrm{Cl}-95 \%$ confidence interval 
occurrence of recurrent changes in the entire group of patients. In IGHV1-69 and in subset \#2 IGHV3-21, higher proportions of deletion $11 \mathrm{q}$ were found ( $30 \%$ and $31 \%$, respectively), with the deletion being present in $19.2 \%$ of the entire group of patients. None of the 3 patients with deletion of $17 \mathrm{p}$ had subset

A

$\mathrm{p}<0.769$ (log-rank test), $\mathrm{HR}=1.09,95 \% \mathrm{Cl}=(0.63,1.89)$

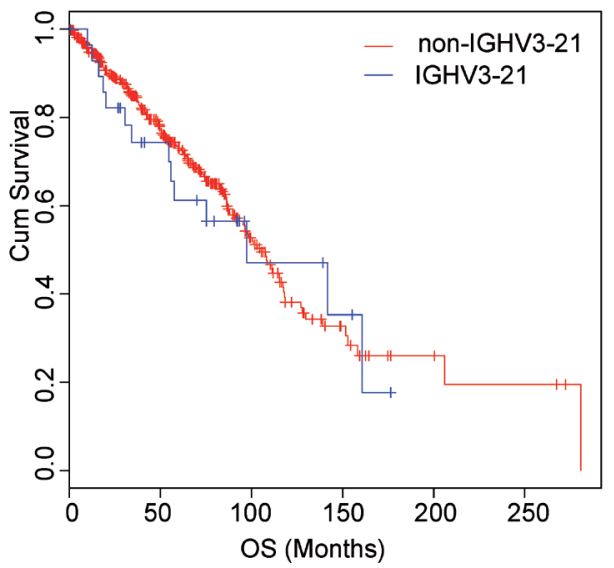

C

$p<0.245$ (log-rank test), HR=0.64, 95\% Cl $=(0.29,1.37)$

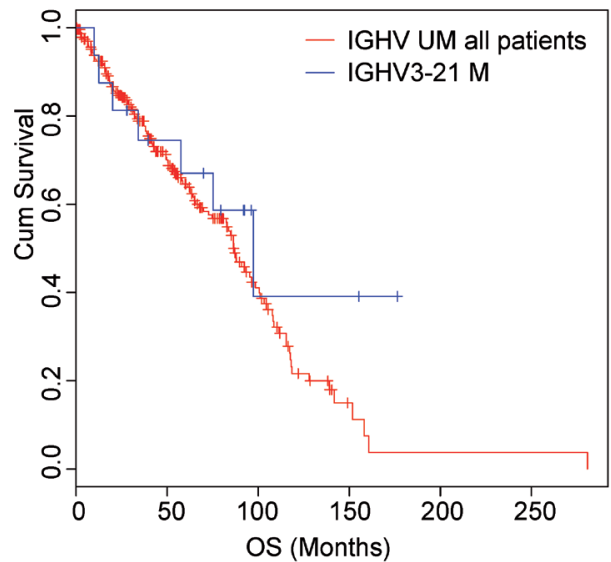

$\mathbf{E}$

$\mathrm{p}<0.302$ (log-rank test), $\mathrm{HR}=0.71,95 \% \mathrm{Cl}=(0.37,1.36)$

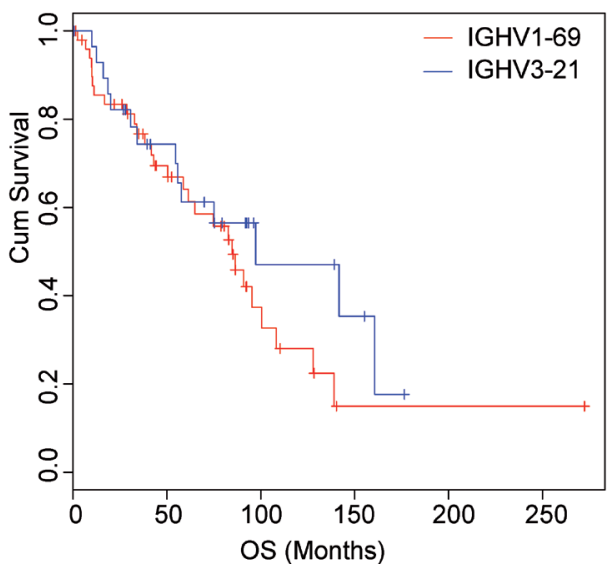

\#2 in IGHV3-21. In patients with IGHV1-69, deletion of $13 q$ was less frequent $(37 \%)$ than in the entire group of patients (46\%). Patients with subset \#2 IGHV3-21 had a higher proportions of deletion of 13 (69\%) as compared with non-subset \#2 IGHV3-21 patients (27\%) (Table 5).

B

$\mathrm{p}<0.597$ (log-rank test), $\mathrm{HR}=0.75,95 \% \mathrm{Cl}=(0.26,2.16)$

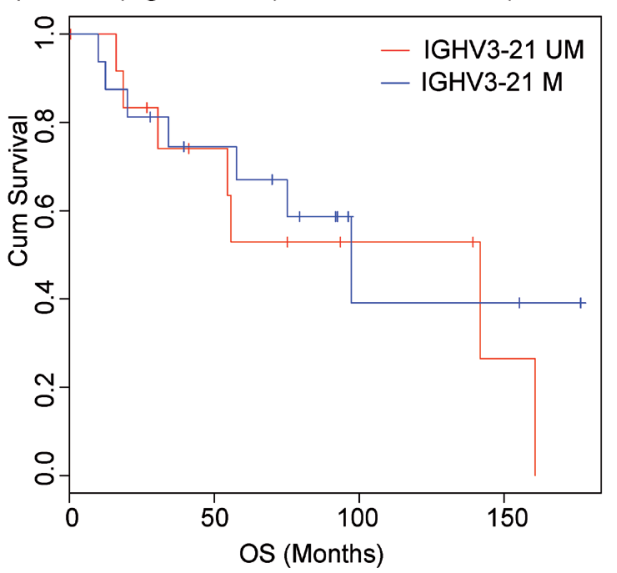

D

$p<0.03$ (log-rank test), $\mathrm{HR}=1.57,95 \% \mathrm{Cl}=(1.04,2.37)$

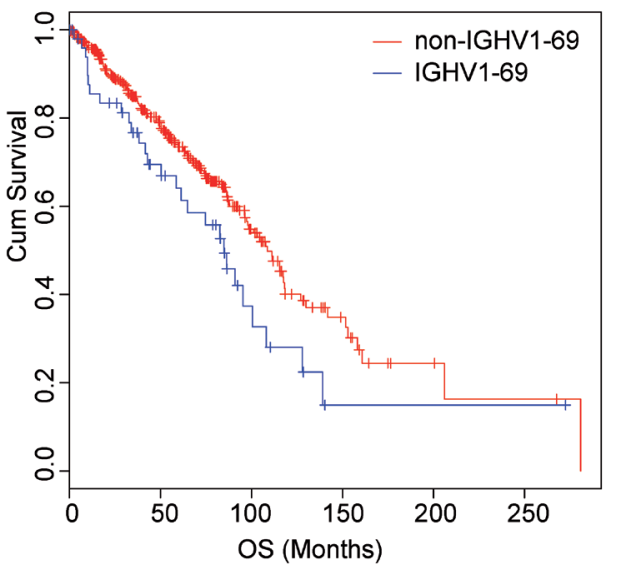

Figure 1. Kaplan-Meier estimates for the overall survival (OS) probability of different CLL subgroups

A The probability of OS was identical in IGHV3-21-positive patients and in non-IGHV3-21 patients $(\mathbf{p}<0.769)$

B The probability of OS was identical in IGHV3-21-positive patients with mutated (M) and unmutated (UM) IGHV status (p<0.597)

C The probability of OS was identical in IGHV3-21-positive patients with M IGHV and all patients with UM IGHV $(\mathrm{p}<0.245)$

D The OS rate of patients with IGHV1-69 was significantly lower in comparison with that of patients with non-IGHV1-69 $(\mathrm{p}<0.03)$

$\mathrm{E}$ The probability of OS was identical in IGHV3-21-positive patients and in IGHV1-69 patients $(\mathrm{p}<0.302)$ 
Excluding recurrent aberration in this group, a total of 4 cases displayed complex cytogenetic aberrations. The complex aberrations were not only heterogeneous but unique in each patient. The losses were detected on chromosomes $3 \mathrm{p}, 6 \mathrm{p}, 7 \mathrm{p}, 9 \mathrm{q}, 14 \mathrm{q}, 18 \mathrm{p}$ and $18 \mathrm{q}$, and gains involved chromosomes $2 \mathrm{p}, 3 \mathrm{q}$ and $18 \mathrm{q}$. Two patients had unbalanced translocations, one of them a jumping translocation with donor chromosome $2 \mathrm{p}$.

In the IGHV1-69 subgene, a total of 51 patients were included and also 4 patients displayed complex karyotypes. As in subgene IGHV3-21, the complex rearrangements were high heterogeneous. Losses in chromosomes $6 \mathrm{q}, 9 \mathrm{p}$ and gains on $2 \mathrm{p}$ and $12 \mathrm{q}$ were detected. An unbalanced translocation involved chromosomes 13 and 18. Composite karyotypes with 55-94 chromosomes were detected in one patient. The frequency of gains and losses was evaluated, showing that losses were more common than gains in both subset.

\section{Discussion}

Numerous studies suggest that in CLL, individual subgenes are not evenly distributed. Certain subgenes are significantly more commonly present, namely the VH1, VH3 and VH4 genes $[7,24]$. Also in the present group of 417 patients, the most frequent genes were VH3 (49.6\%) and VH1 (25.9\%).

In addition to preferential usage of specific IGHV genes, the BCRs of approximately $30 \%$ of CLLs cases are clustered into stereotyped subsets, each of which is characterized by a high degree of homology of the complementarity determining regions (CDRs). Since it is extremely unlikely that two individuals would share identical BCRs, this indicates that CLL development and its natural history is not a random and stochastic event [25]. Importantly, normal B cells carrying stereotyped BCRs similar to those of CLL (and from which CLL may develop) have been identified recently [19].

The presence of certain subgenes is associated with a patient's adverse prognosis, as previously described in the analyzed IGHV3-21 and IGHV1-69 subgenes [10-12, 26]. In the aforementioned group, the IGHV1-69 and IGHV3-21 subgenes were present in $51(12.2 \%)$ and $29(7 \%)$ patients, respectively. The proportion of IGHV3-21 is consistent with geographical distribution of the subgene, being lower than the reported prevalence in Scandinavia (10\%) and slightly higher than that in Southern European countries (5\%) [10].

Table 4. Univariate analysis and multivariate analysis of prognostic factors in relation to OS in all patients

\begin{tabular}{|c|c|c|c|c|c|c|}
\hline \multirow{2}{*}{$\mathrm{N}=417$} & \multicolumn{3}{|c|}{ Univariate analysis } & \multicolumn{3}{|c|}{ Multivariate analysis } \\
\hline & HR & $95 \% \mathrm{Cl}$ & $\mathrm{p}$ & HR & $95 \%$ CI & $\mathrm{P}$ \\
\hline age $\geq 65$ years & 2.31 & $1.65-3.24$ & $<0.001$ & 2.2 & $1.48-3.28$ & $<0.001$ \\
\hline sex (male) & 1.19 & $0.85-1.67$ & $<0.314$ & & & \\
\hline Lymphocyte count $\geq 50\left(10^{9} / \mathrm{L}\right)$ & 2.04 & $1.38-3.02$ & $<0.001$ & 1.82 & $1.18-2.80$ & $<0.05$ \\
\hline Lymphocyte count $\geq 30\left(10^{9} / \mathrm{L}\right)$ & 1.9 & $1.33-2.73$ & $<0.001$ & & & \\
\hline Binet $\mathrm{B}, \mathrm{C}$ stage & 2.05 & $1.45-2.90$ & $<0.001$ & & & \\
\hline $\mathrm{B} 2 \mathrm{M} \geq 2.34(\mathrm{mg} / \mathrm{L})$ & 2.99 & $1.81-4.94$ & $<0.001$ & & & \\
\hline $\mathrm{sTk} \geq 9(\mathrm{U} / \mathrm{L})$ & 2.6 & $1.72-3.94$ & $<0.001$ & & & \\
\hline$I G H V \mathrm{M}$ & 0.35 & $0.24-0.51$ & $<0.001$ & 0.49 & $0.31-0.76$ & $<0.05$ \\
\hline $17 \mathrm{p}-$ & 2.39 & $1.43-3.98$ & $<0.001$ & 2.13 & $1.17-3.87$ & $<0.05$ \\
\hline $11 \mathrm{q}-$ & 1.56 & $1.04-2.33$ & $<0.05$ & & & \\
\hline IGHV1-69 & 1.57 & $1.04-2.37$ & $<0.05$ & & & \\
\hline IGHV3-21 & 1.09 & $0.63-1.89$ & $<0.769$ & & & \\
\hline
\end{tabular}

OS - overall survival, B2M - beta-2-microglobulin, sTk - serum thymidine kinase, IGHV M - immunoglobulin heavy chain variable region mutated(<98\% identity to germline), 11q- - 11q deletion, $17 \mathrm{p}-\mathrm{-17p}$ deletion, $\mathrm{HR}$ - hazard ratio, $95 \% \mathrm{Cl}-95 \%$ confidence interval

Table 5. Recurrent aberrations in IGHV3-21 (subset \#2, non-subset \#2), IGHV1-69 and all patients

\begin{tabular}{|c|c|c|c|c|c|}
\hline Subgroup & & & IGHV3-21 $(\mathrm{N}=29)$ & IGHV1-69 $(\mathrm{N}=51)$ & All CLL $(\mathrm{N}=417)$ \\
\hline Subsets & $\begin{array}{c}\text { Subset \#2 } \\
(\mathrm{N}=13)\end{array}$ & $\begin{array}{c}\text { Non-subset \#2 } \\
\quad(\mathrm{N}=16)\end{array}$ & & & \\
\hline $13 q-$ & $9(69 \%)$ & $4(27 \%)$ & $13(46 \%)$ & $15(37 \%)$ & $46.2 \%$ \\
\hline $11 \mathrm{q}^{-}$ & $4(31 \%)$ & $2(13 \%)$ & $6(21 \%)$ & $12(30 \%)$ & $19.2 \%$ \\
\hline Trisomy 12 & $0(0 \%)$ & $1(7 \%)$ & $1(8 \%)$ & $6(14 \%)$ & $12.0 \%$ \\
\hline $17 \mathrm{p}-$ & $0(0 \%)$ & $3(20 \%)$ & $3(10 \%)$ & $3(7 \%)$ & $7.7 \%$ \\
\hline Complex cytogenetic abnormalities & & & $4(14 \%)$ & $4(10 \%)$ & \\
\hline
\end{tabular}

13q- - 13q deletion, 11q- - 11q deletion, 17p- - 17p deletion, subset \#2 and non-subset \#2 - classified according to defined criteria [5], complex cytogenetic abnormalities - three and more clonal aberrations 
The presence of IGHV1-69 in our group corresponds with the reported occurrence of $10-20 \%$ [27].

On the one side the above studies also suggest that mutations are not uniform within the $\mathrm{V}$ families. Two-thirds of IGHV3-21 patients have M IGHV status, with a relatively low percentage of mutations; on the other side, patients with IGHV1-69 mostly have UM IGHV status $[10,11,26]$. In the present group, M IGHV status was found in 55\% of IGHV3-21 patients, with a mean number of mutations reaching $3.58 \%$. As many as $98 \%$ of IGHV1-69 patients had UM IGHV status. Interestingly, the proportion of males was higher in IGHV1-69 than in IGHV3-21 (76.5\% vs $58.6 \%)$, but the difference was not shown to be significant $(\mathrm{p}=0.08)$.

In the present study, the median OS rates in IGHV3-21 and IGHV1-69 patients were 97 and 85 months, respectively. The rates were not statistically different from the median OS of patients with UM IGHV status which was 86 months. The median survival of patients with M IGHV status was significantly different, reaching 206 months. The differences in median OS rates between patients with $\mathrm{M}$ and those with UM IGHV status are consistent with data published in previous studies [2].

The present detailed observations regarding the predictive value of the other adverse prognostic factors in patients with IGHV3-21 (age $\geq 65$ years, lymphocyte count $\geq 50 \times 10^{9} / \mathrm{L}$ and deletion of 17p) evidenced the group heterogeneity, as reported by some authors admitting varied prognosis within this group of patients $[12,14,16]$. In IGHV1-69 patients, however, the OS was not shown to be influenced by the presence of other adverse prognostic factors, the only exception being deletion of $17 \mathrm{p}$. This demonstrated a relatively high homogeneity of the group, undoubtedly due to almost exclusive proportion of patients with UM IGHV. At the same time, this is consistent with the published data clearly showing that deletion of $17 p$ significantly worsens the prognosis of patients with UM IGHV status [28, 29]. Unlike these published data, the present IGHV3-21 and IGHV1-69 groups were not found to differ in the OS of patients with deletion of 11q.

Multivariate analysis of the entire present group of patients did not show an independent prognostic impact of the presence of the IGHV3-21 and IGHV1-69 subgenes on the patients' OS. When analyzing Binet A stage patients, however, the prognostic role of IGHV3-21 with respect to OS was clearly confirmed.

In a proportion of CLL patients, surface BCR is similar, i.e. stereotyped, suggesting a potential role played by the antigen in leukemogenesis [4-6]. Currently, more than 200 subsets are defined having the stereotyped BCR structure, most of them being subsets 1-8 [30].

Whereas the $I G H V$ mutation status defines various clinical and biological CLL subgroups, determination of stereotyped BCRs does not play the same role [17]. Yet many recent studies were concerned with a preferential link between stereotyped BCRs and some genetic changes [16,31]. It was shown that only some stereotyped BCRs predict the development of genetic and molecular changes subsequently influencing the course of disease. One of them is the stereotyped BCR in patients with IGHV3-21, subset \#2 [12,16,17,32]. A recent study on subset \#2 was concerned with not only assessment of recurrent aberrations but also analysis of mutations, showing a significantly specific genetic and molecular pattern with a high occurrence of the SF3B1 mutation, more frequent deletions of $13 \mathrm{q}$ and $11 \mathrm{q}$ and, conversely, the absence of trisomy 12 and deletion of 17p [17]. The present group of patients with subset \#2 was characterized by a high frequency of deletion of $11 \mathrm{q}(31 \%)$ and a higher occurrence of deletion of $13 \mathrm{q}(69 \%)$ as compared with non-subset \#2 patients ( $13 \%$ and $27 \%$, respectively) and the entire group ( $19.2 \%$ and $46.2 \%$, respectively). None of 3 patients with deletion of $17 \mathrm{p}$ in IGHV3-21 had subset \#2. The same observations were reported by other authors $[16,17]$. In the IGHV3-21 and IGHV1-69 groups, we detected recurrent gains of $2 p$ in two patients, as published earlier. This aberration was associated with UM IGHV status and an advanced stage of the disease [33].

To conclude with, CLL patients with the IGHV3-21 and IGHV1-69 subgenes have as adverse prognosis as the other patients with UM IGHV status. The presence of deletion of $17 \mathrm{p}$ makes OS in both groups even shorter. In IGHV3-21 patients, OS is influenced by other predictive factors and the subgene itself is an independent prognostic factor in patients with Binet A stage CLL. The data presented in the study show that the patients constitute a biologically rather interesting heterogeneous CLL subset that should be intensively investigated.

Supplementary information is available in the online version of the paper.

Acknowledgements: Supported by research projects LF-2014-001 and Grant IGA NT 13576-4 from the Ministry of Health, Czech Republic.

\section{References}

[1] CAI J, HUMPHRIES C, RICHARDSON A, TUCKER PW. Extensive and selective mutation of a rearranged VH5 gene in human B cell chronic lymphocytic leukemia. J Exp Med 1992; 176: 073-1081. http://dx.doi.org/10.1084/jem.176.4.1073

[2] HAMBLIN TJ, DAVIS Z, GARDINER A, OSCIER DG, STEVENSON FK. Unmutated Ig $\mathrm{V}(\mathrm{H})$ genes are associated with a more aggressive form of chronic lymphocytic leukemia. Blood 1999; 94: 1848-1854.

[3] DAMLE RN, WASIL T, FAIS F, GHIOTTO F, VALETTO A, et al. Ig V gene mutation status and CD38 expression as novel prognostic indicators in chronic lymphocytic leukemia. Blood 1999; 94: 1840-1847.

[4] MATTHEWS C, CATHERWOOD MA, MORRIS TC, ALEXANDER HD. $\mathrm{V}(\mathrm{H}) 3-48$ and $\mathrm{V}(\mathrm{H}) 3-53$ as well as $\mathrm{V}(\mathrm{H}) 3-21$, gene rearrangements define unique subgroups in CLL and are associated with biased lambda light chain restriction, homologous LCDR3 sequences and poor prognosis. Leuk Res 2007; 31: 231-234. http://dx.doi.org/10.1016/j. leukres.2006.03.028 
[5] TOBIN G, THUNBERG U, JOHNSON A, ERIKSSON I, SODERBERG O, et al. Chronic lymphocytic leukemias utilizing the VH3-21 gene display highly restricted Vlambda2-14 gene use and homologous CDR3s: implicating recognition of a common antigen epitope. Blood 2003; 101: 4952-4957. http://dx.doi.org/10.1182/blood-2002-11-3485

[6] HERVE M, XU K, NG YS, WARDEMANN H, ALBESIANO E, et al. Unmutated and mutated chronic lymphocytic leukemias derive from self-reactive B cell precursors despite expressing different antibody reactivity. J Clin Invest 2005; 115: 1636-1643. http://dx.doi.org/10.1172/JCI24387

[7] PRITSCH O, TROUSSARD X, MAGNAC C, MAURO FR, DAVI $F$, et al. VH gene usage by family members affected with chronic lymphocytic leukaemia. Br J Haematol 1999; 107: 616624. http://dx.doi.org/10.1046/j.1365-2141.1999.01757.x

[8] SCHROEDER HW JR, DIGHIERO G. The pathogenesis of chronic lymphocytic leukemia: analysis of the antibody repertoire. Immunol Today 1994; 15: 288-294. http://dx.doi. org/10.1016/0167-5699(94)90009-4

[9] FAIS F, GHIOTTO F, HASHIMOTO S, SELLARS B, VALETTO A, et al. Chronic lymphocytic leukemia B cells express restricted sets of mutated and unmutated antigen receptors. J Clin Invest 1998; 102: 1515-1525. http://dx.doi.org/10.1172/ JCI3009

[10] TOBIN G, THUNBERG U, JOHNSON A, THORN I, SODERBERG O, et al. Somatically mutated $\mathrm{Ig} \mathrm{V}(\mathrm{H}) 3-21$ genes characterize a new subset of chronic lymphocytic leukemia. Blood 2002; 99: 2262-2264. http://dx.doi.org/10.1182/blood. V99.6.2262

[11] PANOVSKA-STAVRIDIS I, IVANOVSKI M, SILJANOVSKI N, CEVRESKA L, EFREMOV DG. Chronic lymphocytic leukemia patients with a V1-69 gene rearrangement do not have inferior survival with respect to patients that express other unmutated V(H) genes. Leuk Res 2007; 31: 245-248. http://dx.doi.org/10.1016/j.leukres.2006.05.008

[12] THORSELIUS M, KROBER A, MURRAY F, THUNBERG U, TOBIN G, et al. Strikingly homologous immunoglobulin gene rearrangements and poor outcome in $\mathrm{VH} 3$-21-using chronic lymphocytic leukemia patients independent of geographic origin and mutational status. Blood 2006; 107: 2889-2894. http://dx.doi.org/10.1182/blood-2005-06-2227

[13] GHIA EM, JAIN S, WIDHOPF GF, 2ND, RASSENTI LZ, KEATING MJ, et al. Use of IGHV3-21 in chronic lymphocytic leukemia is associated with high-risk disease and reflects antigen-driven, post-germinal center leukemogenic selection. Blood 2008; 111: 5101-5108. http://dx.doi.org/10.1182/blood$\underline{2007-12-130229}$

[14] STAMATOPOULOS K, BELESSI C, MORENO C, BOUDJOGRAH M, GUIDA G, et al. Over $20 \%$ of patients with chronic lymphocytic leukemia carry stereotyped receptors: Pathogenetic implications and clinical correlations. Blood 2007; 109: 259-270. http://dx.doi.org/10.1182/blood-2006$\underline{03-012948}$

[15] BOMBEN R, DAL BO M, CAPELLO D, FORCONI F, MAFFEI R, et al. Molecular and clinical features of chronic lymphocytic leukaemia with stereotyped B cell receptors: results from an Italian multicentre study. Br J Haematol
2009; 144: 492-506. http://dx.doi.org/10.1111/j.1365-2141 2008.07469.x

[16] MARINCEVIC M, CAHILL N, GUNNARSSON R, ISAKSSON A, MANSOURI M, et al. High-density screening reveals a different spectrum of genomic aberrations in chronic lymphocytic leukemia patients with ,stereotyped IGHV3-21 and IGHV4-34 B-cell receptors. Haematologica 2010; 95: 1519-1525. http://dx.doi.org/10.3324/ haematol.2009.021014

[17] ROSSI D, SPINA V, BOMBEN R, RASI S, DAL-BO M, et al. Association between molecular lesions and specific B-cell receptor subsets in chronic lymphocytic leukemia. Blood 2013; 121: 4902-4905. http://dx.doi.org/10.1182/blood-2013 $\underline{-02-486209}$

[18] WIDHOPF GF, 2ND, GOLDBERG CJ, TOY TL, RASSENTI LZ, WIERDA WG, et al. Nonstochastic pairing of immunoglobulin heavy and light chains expressed by chronic lymphocytic leukemia B cells is predicated on the heavy chain CDR3. Blood 2008; 111: 3137-3144. http://dx.doi. org/10.1182/blood-2007-02-073130

[19] FORCONI F, POTTER KN, WHEATLEY I, DARZENTAS N, SOZZI E, et al. The normal IGHV1-69-derived B-cell repertoire contains stereotypic patterns characteristic of unmutated CLL. Blood 2010; 115: 71-77. http://dx.doi.org/10.1182/ blood-2009-06-225813

[20] JAROSOVA M, JEDLICKOVA K, HOLZEROVA M, URBANOVA R, PAPAJIK T, et al. Contribution of comparative genomic hybridization and fluorescence in situ hybridization to the detection of chromosomal abnormalities in B-cell chronic lymphocytic leukemia. Onkologie 2001; 24: 60-65. http://dx.doi.org/10.1159/000050284

[21] VAN DONGEN JJ, LANGERAK AW, BRUGGEMANN M, EVANS PA, HUMMEL M, et al. Design and standardization of PCR primers and protocols for detection of clonal immunoglobulin and $\mathrm{T}$-cell receptor gene recombinations in suspect lymphoproliferations: report of the BIOMED-2 Concerted Action BMH4-CT98-3936. Leukemia 2003; 17: 2257-2317. http://dx.doi.org/10.1038/sj.leu.2403202

[22] GONZALEZ-GASCON YMI, HERNANDEZ JA, MARTIN A, ALCOCEBA M, SARASQUETE ME, et al. Mutation status and immunoglobulin gene rearrangements in patients from northwest and central region of Spain with chronic lymphocytic leukemia. Biomed Res Int 2014; 2014: 257517. http://dx.doi.org/10.1155/2014/257517

[23] BROCHET X, LEFRANC MP, GIUDICELLI V. IMGT/VQUEST: the highly customized and integrated system for IG and TR standardized V-J and V-D-J sequence analysis. Nucleic Acids Res 2008; 36: W503-508. http://dx.doi.org/10.1093/nar/ gkn316

[23] CHESON BD, BENNETT JM, GREVER M, KAY N, KEATING MJ, et al. National Cancer Institute-sponsored Working Group guidelines for chronic lymphocytic leukemia: revised guidelines for diagnosis and treatment. Blood 1996; 87: 4990-4997.

[24] JOHNSON TA, RASSENTI LZ, KIPPS TJ. Ig VH1 genes expressed in B cell chronic lymphocytic leukemia exhibit distinctive molecular features. J Immunol 1997; 158: 235-246. 
[25] GAIDANO G, FOA R, DALLA-FAVERA R. Molecular pathogenesis of chronic lymphocytic leukemia. J Clin Invest 2012; 122: 3432-3438. http://dx.doi.org/10.1172/JCI64101

[26] ORLANDI EM, ZIBELLINI S, PASCUTTO C, PICONE C, GIARDINI I, et al. IGHV unmutated status influences outcome more than IGHV1-69 gene usage per se in patients with chronic lymphocytic leukemia. Clin Lymphoma Myeloma 2009; 9: 390-393. http://dx.doi.org/10.3816/ CLM.2009.n.076

[27] POTTER KN, ORCHARDJ, CRITCHLEY E, MOCKRIDGE CI, JOSE A, et al. Features of the overexpressed V1-69 genes in the unmutated subset of chronic lymphocytic leukemia are distinct from those in the healthy elderly repertoire. Blood 2003; 101: 3082-3084. http://dx.doi.org/10.1182/blood-2002-08-2432

[28] STILGENBAUER S, BULLINGER L, LICHTER P, DOHNER H, GERMAN CLLSGCLL. Genetics of chronic lymphocytic leukemia: genomic aberrations and $\mathrm{V}(\mathrm{H})$ gene mutation status in pathogenesis and clinical course. Leukemia 2002; 16: 993-1007. http://dx.doi.org/10.1038/sj.leu.2402537

[29] STILGENBAUER S, LICHTER P, DOHNER H. Genetic features of B-cell chronic lymphocytic leukemia. Rev Clin Exp Hematol 2000; 4: 48-72. http://dx.doi.org/10.1046/j.1468$\underline{0734.2000 .00003 . \mathrm{x}}$
[30] AGATHANGELIDIS A, DARZENTAS N, HADZIDIMITRIOU A, BROCHET X, MURRAY F, et al. Stereotyped $\mathrm{B}$-cell receptors in one-third of chronic lymphocytic leukemia: a molecular classification with implications for targeted therapies. Blood 2012; 119: 4467-4475. http://dx.doi.org/10.1182/ blood-2011-11-393694

[31] ATHANASIADOU A, STAMATOPOULOS K, GAITATZI M, STAVROYIANNI N, FASSAS A, et al. Recurrent cytogenetic findings in subsets of patients with chronic lymphocytic leukemia expressing IgG-switched stereotyped immunoglobulins. Haematologica 2008; 93: 473-474. http://dx.doi.org/10.3324/ haematol.11872

[32] BOMBEN R, DAL BO M, CAPELLO D, BENEDETTI D, MARCONI D, et al. Comprehensive characterization of IGHV3-21-expressing B-cell chronic lymphocytic leukemia: an Italian multicenter study. Blood 2007; 109: 2989-2998.

[33] JAROSOVA M, URBANKOVA H, PLACHY R, PAPAJIK T, HOLZEROVA M, et al. Gain of chromosome $2 p$ in chronic lymphocytic leukemia: significant heterogeneity and a new recurrent dicentric rearrangement. Leuk Lymphoma 2010; 51: 304-313. http://dx.doi. org/10.3109/10428190903518311 